\title{
OPTIMIZATION STUDY ON TOW HOOK OF A COMMERCIAL VEHICLE TO IMPROVE THE PERFORMANCE AT DIFFERENT LOADING CONDITIONS
}

\author{
G Pruthvi Raj ${ }^{1}$, Ganesha $B^{2}$ \\ ${ }^{1}$ P.G. Student, Mechanical Engineering Department, B.I.T.M., Bellary \\ ${ }^{2}$ Associate Professor, Mechanical Engineering Department, B.I.T.M., Bellary
}

\begin{abstract}
Growing competition in automotive market makes it more and more necessary to reduce the development time and cost of the product development process. One of the most costly phases in the vehicle development process is the field durability test and high expenses for this phase can be attributed to the number of prototypes used and time needed for its execution. Also, multiple iterations of designing, building and testing prototypes are no longer affordable against the time and cost constraints for developing a competitive product. It became necessary to come up with innovative solutions which are cost effective and effective and at the same time which will meet the performance requirement, to sustain in growing market. A step towards frugal engineering, engineering is to replace number of subassemblies in the vehicle with a single multifunctional invention. Today, analytical tools in the form of computer simulation have been developed to such a level that they reliably predict performance. Hardware prototypes cannot be made in early design phase, however, today with the use of Computer Aided Engineering tools virtual models can be created to accurately represent physical models and to take right decisions at the right time. Design of integrated multifunctional module for Heavy commercial vehicle will replace various subsystem including Towing device mountings, Suspension mounting systems, cabinet mounting systems with single design.
\end{abstract}

This dissertation work involves evaluation of various loads coming on the tow hook model during different working conditions. Based on these loadings and space available the model will be designed which will meet the structural performance criteria. The main objective of the project is to lower the weight and cost of component, and provide more robust design to customer.

Keywords: Tow hook, static analysis and Modal analysis.

\section{INTRODUCTION}

The need for portability of equipment has increased manifold times today. In today's scenario due to competition it is essential to have equipment with lowest cost of design, production and operation. Design of the equipment plays a vital role; hence the handling and utilization of the equipment should be quicker and user-friendly. In case of transporting heavy disabled buses, truck tractors, or large trucks a tow hook can be used[5].

A tow hook helps in transporting vehicles, industrial equipment from one place to another. A tow hook is attached to the chassis of a vehicle for towing. A tow hook needs to have good vertical and sideways strength and depending on the size of your trailer and the loads you wish to carry, this will determine the size of the material required and the design that you should use. The cross section of tow hook can be circular, square or rectangular. Square and rectangular sections make the structure more robust; however, it increases the stress concentration at edges and is likely to fail after a certain number of stress cycles. Circular section gives uniform stress concentration throughout; however, it has lesser load pulling capacity as compared to the other sections[3]. The tow hook is mounted on the frame of the towed unit, with a receiver mounted under the frame of the car.

As tow hook design plays vital role in towing of the vehicle, it should be designed as per the standards as well as material should be selected and analyzed to improve the performance of the hook in different loading conditions. The artificial sizing and weighting must be designed to withstand the greater weight of the towed vehicle, which might otherwise tip the tow truck back[2].

\section{TOWING}

It is combined with two or lot objects along so they'll be force by a chosen power supply or sources. The towing source supply could also be a motorized land vehicle for carrying such as vesse1, animal or human the load something which will be pulled. These could also be joined by a series of hitch, chain, rope, bar, , three-point, coupling, drawbar, fifth wheel, integrated platform, or alternative means of keeping the objects along whereas in motion[4]. The main goal of the present work is to optimize the tow hook designs to improve the performance on different loading conditions by conducting static and modal analysis. And some other main objectives of work are, 
- To assess the dynamic interaction between a component and its supporting structure

- To evaluate design changes using natural frequencies and normal modes

- Normal mode analysis for the Tow hooks assembly to attain the fundamental natural frequency (first natural frequency).

- $\quad$ To evaluate the effects of steady loading conditions on structure

- To reduce the component cost by reducing the weight and to provide robust design by suggesting the proper material to the design

It is vital that the correct material and section type is used to ensure that each part will be able to endure the load it will experience; hence proper material grade selection should be done to improve the life of the component.

\section{METHODOLOGY OF THE WORK}

The procedure followed in order to do the analysis work is done by initially taking the two tow hook models. Modal analysis is carried out for the two designs considered by meshing the tow hooks and applying the boundary conditions, where the meshing and analysis is done in ALTAIR-HYPERWORKS V12. Static analysis is done by taking the best model along with the whole assembly and a static load is applied over the structure. Different loading conditions and different materials are considered for the analysis which are done by NASTRAN software as a tool. The obtained results are viewed in HYPERVIEW and graphs are plotted for each of the results obtained.

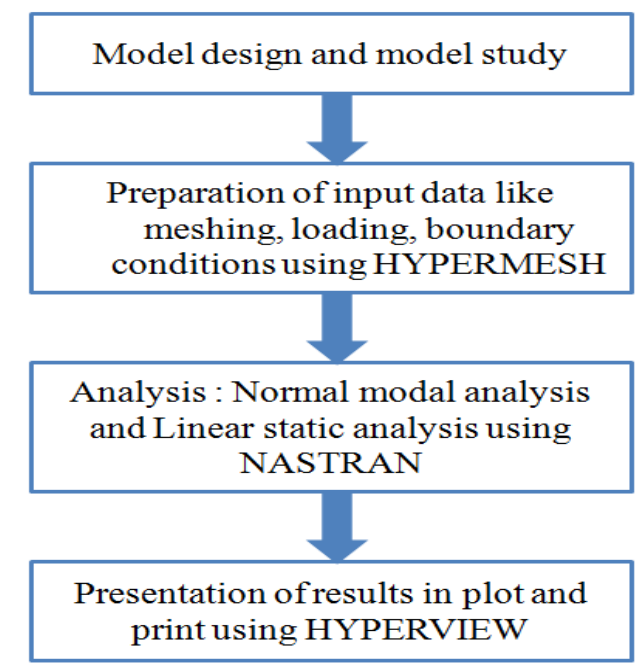

Fig 1: Flow chart of Tow hook analysis

\section{MATERIAL PROPERTIES AND DESIGN OF TOW HOOK}

In this topic concepts of tow hook are studied in order to set the boundary condition to obtain better accuracy in the results after analysis, also selection of materials and their properties are discussed in brief.

\subsection{Model Selection and Study}

Two tow hook models are taken for the analysis study which is represented in the following figures.
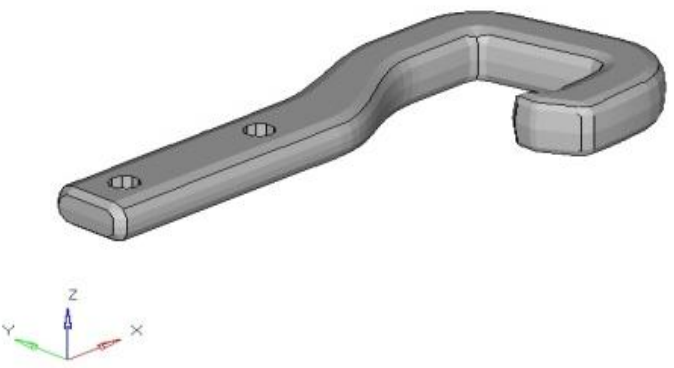

Fig 2: Tow hook model 1

The above figure shows the modell taken for the analysis work.

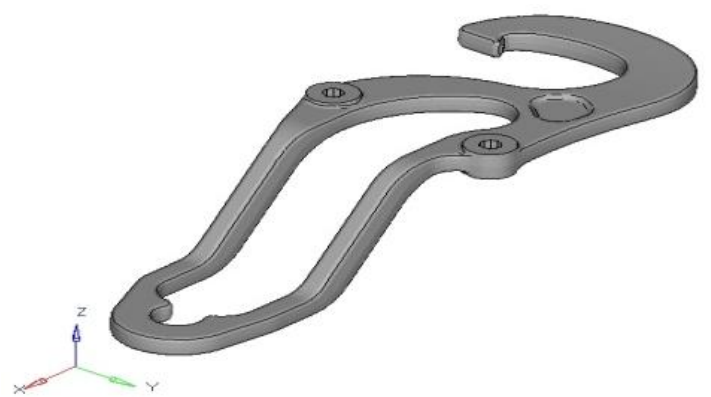

Fig 3: Tow hook model 2

Both of the models shown in the above figures are considered for the modal analysis in order to find the natural frequencies and the mode shapes, among which the model with the highest natural frequency are subjected to static load with different loading conditions and different material considerations.

Figure 4 shows tow hook assembly, in which various supporting components are attached to the tow hook.

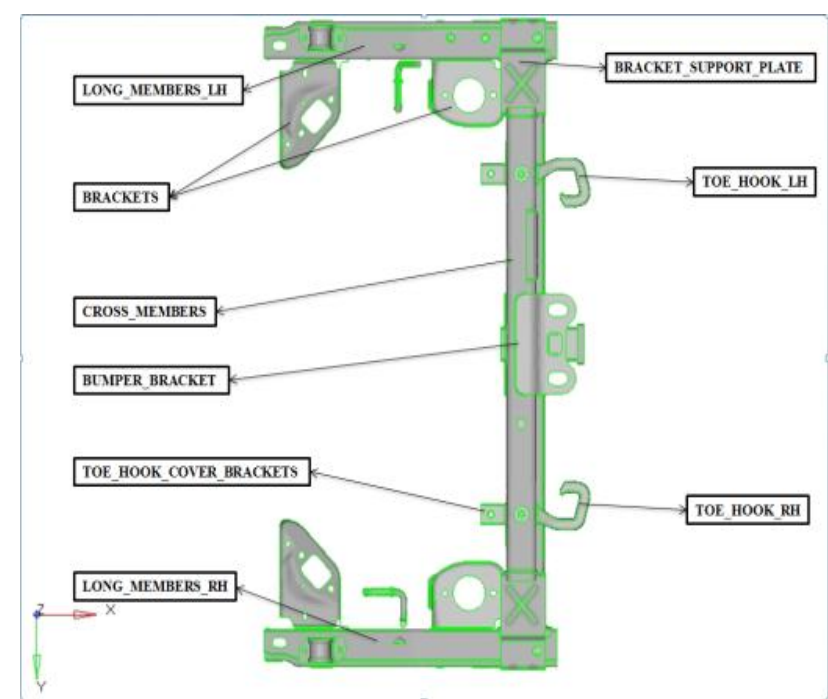

Fig 4: Complete Representation of Tow Hook Assembly 


\subsection{Material}

It is important to choose the correct material and section type is used to ensure that each part will be able to endure the load it will experience. The type of material to be used for tow bar depends on its application requirements and operating conditions. The material is decided on the basis of its rigidity, strength, cost, durability and reliability. The material selected should also be easy to fabricate. Fabrication plays an important role in material selection. As strength of material increases, cost of fabrication increases.

Stainless steel started to be used as material for decoration in automobile. However, in recent years, it is mostly used as material for the tow hook. It is because those stainless steels with good performance of high temperature characteristics and high corrosion resistance[1]. Material used for structural analysis of Tow hook is listed in Table1.The isotropic material properties used in a FEA analysis are as follows.

Table 1: Mechanical properties of materials used in Tow hook analysis

\begin{tabular}{|l|l|l|l|l|}
\hline $\begin{array}{l}\text { Sl. } \\
\text { No. }\end{array}$ & $\begin{array}{l}\text { Mechanical } \\
\text { property }\end{array}$ & $\begin{array}{l}\text { Stainless } \\
\text { Steel }\end{array}$ & $\begin{array}{l}\text { Aluminu } \\
\text { m Alloy }\end{array}$ & $\begin{array}{l}\text { Cast } \\
\text { Iron }\end{array}$ \\
\hline 1 & $\begin{array}{l}\text { Young's } \\
\text { Modulus(E) }\end{array}$ & $\begin{array}{l}2.08 \times 10^{5} \\
\mathrm{~N} / \mathrm{mm}^{2}\end{array}$ & $\begin{array}{l}0.70 \times 10^{5} \\
\mathrm{~N} / \mathrm{mm}^{2}\end{array}$ & $\begin{array}{l}1.20 \times 10^{5} \\
\mathrm{~N} / \mathrm{mm}^{2}\end{array}$ \\
\hline 2 & $\begin{array}{l}\text { Poisson's } \\
\text { Ratio(v) }\end{array}$ & 0.31 & 0.35 & 0.28 \\
\hline 3 & Density $(\rho)$ & $\begin{array}{l}7.85 \times 10^{-} \\
9\end{array}$ & $\begin{array}{l}2.7 \times 10^{-9} \\
\text { Ton } / \mathrm{mm}^{3}\end{array}$ & $\begin{array}{l}7.20 \times 10^{-} \\
\text {Ton } / \mathrm{mm}\end{array}$ \\
\hline 4 & $\begin{array}{l}\text { Yield } \\
\text { Stress }\left(\mathrm{e}_{\mathrm{y}}\right)\end{array}$ & $350 \mathrm{~N} / \mathrm{mm}^{2}$ & $\begin{array}{l}200-600 \\
\mathrm{~N} / \mathrm{mm}^{2}\end{array}$ & $\begin{array}{l}85 \\
\mathrm{~N} / \mathrm{mm}^{2}\end{array}$ \\
\hline
\end{tabular}

\subsection{Boundary conditions and modal analysis}

The proper specification of boundary conditions is just as important for dynamic analysis as it is for static analysis. The improper specification of the boundary conditions leads to incorrect answers. One such improper specification of boundary conditions is forgetting to fully constrain the structure. Unlike static analysis, for which an under constrained model does not run, an under-constrained model does run in dynamic analysis. We should perform a Normal mode analysis first and verify that there are no unwanted rigid-body modes.

The boundary condition is set for the modellas shown in fig.5, which indicates that it is in the fixed condition since it the fixed part in the whole assembly of the part.

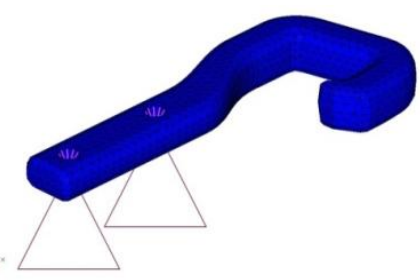

Fig 5: Boundary Condition of Tow hook model1
The model1 shows the boundary conditions applied on the model taken for the analysis. The boundary condition is indicated by the triangle shapes.

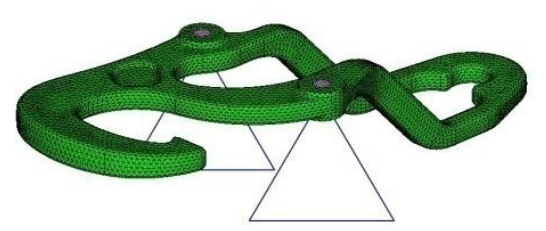

Fig 6: Boundary condition applied on model 2

Once the boundary conditions are applied on both the models, the natural frequencies and mode shapes are found by using HYPERMESH software which are listed in the below tables.

Table 2: Mode Shapes on Different Natural Frequency of Tow hook model1

\begin{tabular}{|l|l|l|l|}
\hline $\begin{array}{l}\text { SL. } \\
\text { No }\end{array}$ & Modes shapes & Description & $\begin{array}{l}\text { Natural frequency } \\
(\mathbf{H z})\end{array}$ \\
\hline 1 & $1^{\text {st }}$ Mode & Bending mode & $4.947 \mathrm{E} 2$ \\
\hline 2 & $2^{\text {nd }}$ Mode & Lateral mode & $5.950 \mathrm{E} 2$ \\
\hline 3 & $3^{\text {rd }}$ Mode & Torsion mode & $1.230 \mathrm{E} 3$ \\
\hline 4 & $4^{\text {th }}$ Mode & Lateral mode & $1.351 \mathrm{E} 3$ \\
\hline
\end{tabular}

The table 2 shows the dirrent values of nautral frequencies and mode shapes obtained for design 1 .

Table 3: Mode Shapes on Different Natural Frequency of Tow hook model 2

\begin{tabular}{|l|l|l|l|}
\hline $\begin{array}{l}\text { SL. } \\
\text { No }\end{array}$ & $\begin{array}{l}\text { Modes } \\
\text { shapes }\end{array}$ & Description & $\begin{array}{l}\text { Natural } \\
\text { frequency } \\
(\mathbf{H z})\end{array}$ \\
\hline 1 & $1^{\text {st }}$ Mode & $\begin{array}{l}\text { Bending } \\
\text { mode }\end{array}$ & $2.627 \mathrm{E} 2$ \\
\hline 2 & $2^{\text {nd }}$ Mode & Linear mode & $2.959 \mathrm{E} 2$ \\
\hline 3 & $3^{\text {rd }}$ Mode & Lateral mode & $3.678 \mathrm{E} 2$ \\
\hline 4 & $4^{\text {th }}$ Mode & $\begin{array}{l}\text { Bending } \\
\text { mode }\end{array}$ & $7.133 \mathrm{E} 2$ \\
\hline
\end{tabular}

The table 3 shows the various range of values obtained for design2. By comparing design iterations of normal mode analysis the first fundamental natural frequency of tow hook design 1 and tow hook design 2 are $494.7 \mathrm{~Hz}(1.151 \mathrm{e}-$ 03Tons) and $262.7 \mathrm{~Hz}(4.206 \mathrm{e}-03 \mathrm{Ton})$ respectively. When compared to masses of the tow hook, the design 1 gives the optimum mass and the natural frequency for design 1 satisfies the design standards so design 1 is considered further analysis such as static analysis. Mode shape vs natural frequencies of both designs are compared using graph shown in figure 7 . In the graph the blue line indicates the natural frequency range for the modell and the blue line indicates the natural frequency ranges of the model 2 which are taken for the modal analysis. 


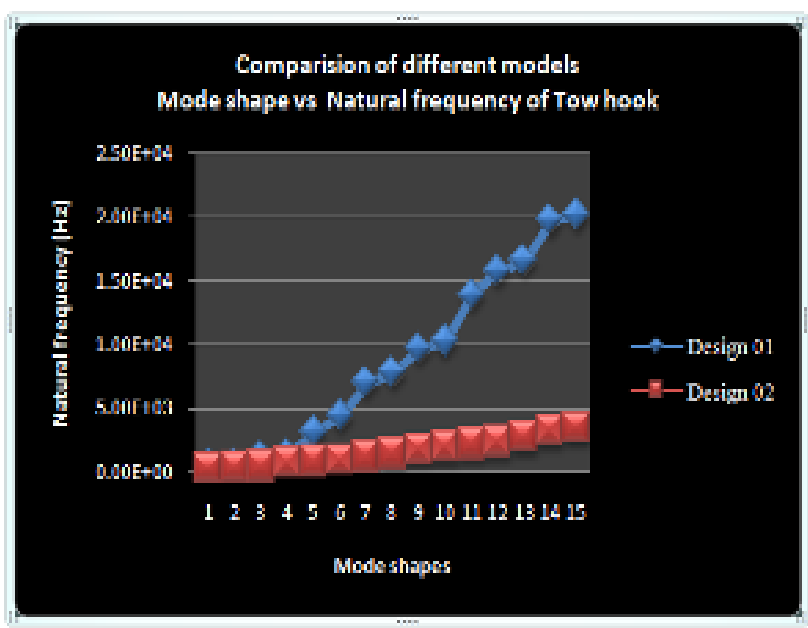

Fig 7: Comparison of mode shape v/s natural frequency of two models of Tow hook.

\subsection{Static analysis}

Static analysis is employed to know the maximum stress developed on the Tow hook and also the displacement and reaction forces at the Tow and bracket location. The name Static indicates that the load on the Tow hook is constant, and load is not varying with respect to time. Before analysis the structure is meshed for finite meshing in HYPERMESH software. Static analysis is performed with $6 \mathrm{KN}$ load applied as body force in pull, push, $30^{\circ}$ up and $30^{\circ}$ down directions. The boundary conditions are applied and all degrees of freedom(DOF) in the cross member location are constrained. The displacements of tow hook assembly for different materials are separately obtained and compared at different loading conditions. The materials considered for the analysis in order to fond the stress and displacement at different loading condition are stainless steel, Aluminium, and Cast iron.

\section{Load Case 1: Pull Load}

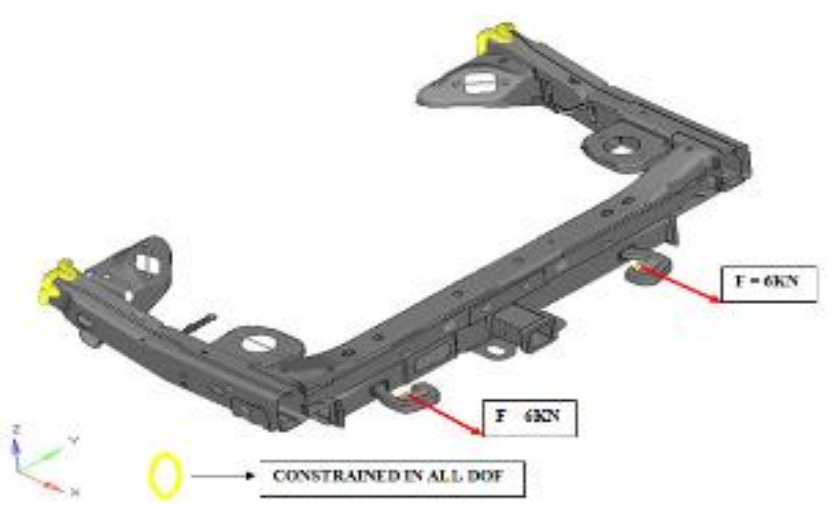

Fig 8: Loading and boundary condition for pull load.

In the first case for the static analysis pull load is considered, where the vehicle has to be dragged out whenever it is in trouble or problem. Other three conditions taken in the analysis are shown by the different figures as listed below.

\section{Load Case 2: Push Load}

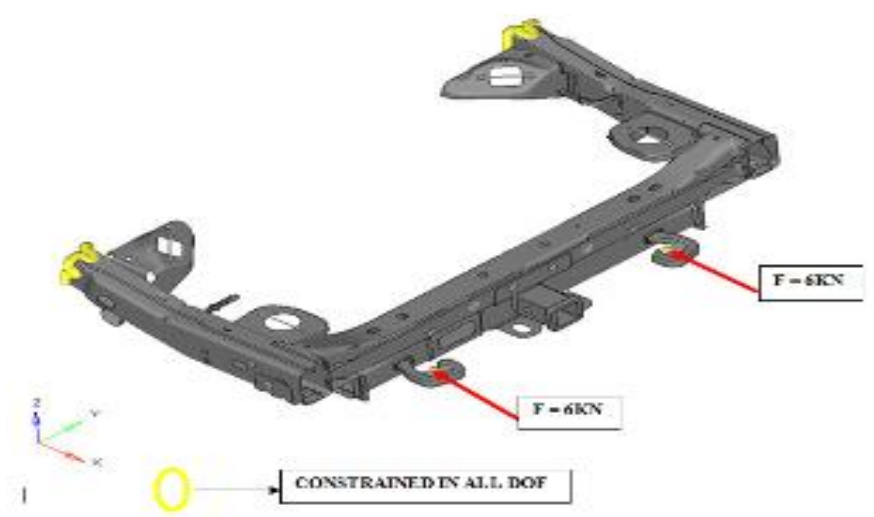

Fig 9: Loading and boundary condition for push Load

Pull loading is considered when our vehicle has to be dragged out and push loading is considered when others vehicles has to be dragged out. The other two loading condition are $30^{\circ}$ download and $30^{\circ}$ upload which are represented by following two figures.

\section{Load Case 3: 30 Down Load}

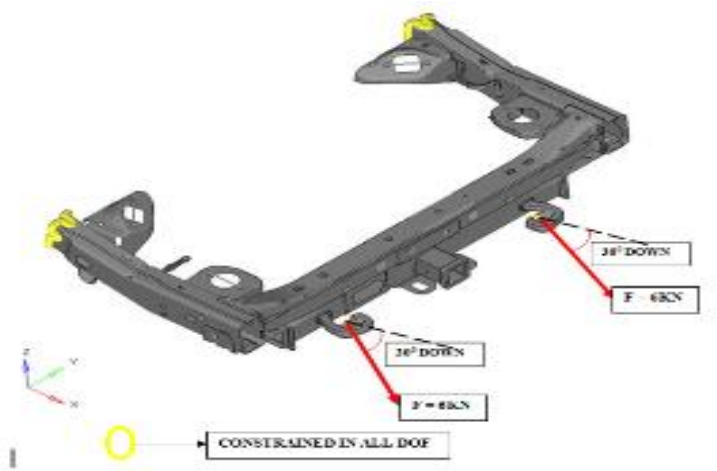

Fig 10: Loading and boundary condition for $30^{\circ}$ down.

The third case is for the $30^{\circ}$ loading for the down load codition

\section{Load Case 4: $30^{0}$ Up Load}

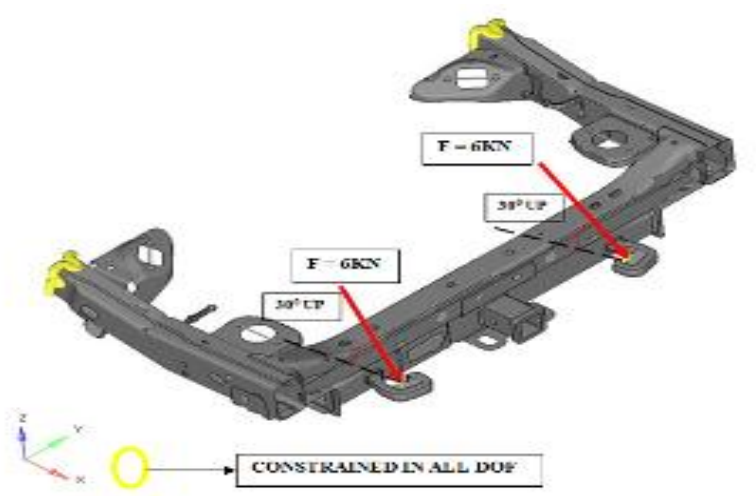

Fig 11: Loading and boundary condition for $30^{\circ} \mathrm{up}$. The $30^{\circ}$ loading and boundary conditions for pull loadings are described in the above figures. The obtained results are tabulated for stress, displacement for both tow hook alone and whole assembly for different materials are as listed below. 
Table4: Property analysis of aluminium on different loading conditions

\begin{tabular}{|c|c|c|c|c|}
\hline $\begin{array}{l}\text { SI } \\
\text { no. }\end{array}$ & Force(6KN) & $\begin{array}{l}\text { Displacement of } \\
\operatorname{model}(\mathbf{m m})\end{array}$ & $\begin{array}{l}\text { Stress of } \\
\text { Model } \\
\left(\mathbf{N} / \mathbf{m m}^{2}\right)\end{array}$ & $\begin{array}{l}\text { Stress of } \\
\text { Tow Hook } \\
\left(\mathrm{N} / \mathrm{mm}^{2}\right)\end{array}$ \\
\hline 1 & Pull & 7.8 & 341.2 & 203.3 \\
\hline 2 & Push & 7.8 & 341.2 & 203.3 \\
\hline 3 & $30^{0}$ up & 6.5 & 335.2 & 201.2 \\
\hline 4 & $30^{0}$ down & 16.4 & 478.8 & 244.3 \\
\hline
\end{tabular}

The above table shows the values of stress and displacement which are relatively high.

Table 5: Property analysis of Cast iron on different loading

\begin{tabular}{|l|l|l|l|l|}
\hline $\begin{array}{l}\text { SI } \\
\text { no. }\end{array}$ & Force (6KN) & $\begin{array}{l}\text { Displace } \\
\text { ment of } \\
\text { model } \\
(\mathbf{m m})\end{array}$ & $\begin{array}{l}\text { Stress of } \\
\begin{array}{l}\text { Model } \\
\left(\mathbf{N} / \mathbf{m m}^{2}\right)\end{array}\end{array}$ & $\begin{array}{l}\text { Stress of } \\
\text { Tow Hook } \\
\left(\mathbf{N} / \mathbf{m m}^{2}\right)\end{array}$ \\
\hline 1 & Pull & 4.5 & 349.4 & 214.1 \\
\hline 2 & Push & 4.5 & 349.4 & 214.1 \\
\hline 3 & $30^{0}$ up & 3.8 & 275.2 & 209.8 \\
\hline 4 & $30^{0}$ down & 9.6 & 479.8 & 256.2 \\
\hline
\end{tabular}

Stress and displacement values obtained for Cast iron are as listed shown in above table.

Stainless steel values are listed in the below table. With these values the graphs are plotted for different aspects and the comparisons are made.

The stress and the displacement values obtained for stainless steel is comparatively very low to that of the cast iron and aluminium material.

Table6: Property analysis of Stainless Steel on different loading conditions

\begin{tabular}{|l|l|l|l|l|}
\hline $\begin{array}{l}\text { Sl } \\
\text { no. }\end{array}$ & Force(6KN) & $\begin{array}{l}\text { Displacement } \\
\text { of } \\
\text { model(mm) }\end{array}$ & $\begin{array}{l}\text { Stress of } \\
\left.\text { Model(N/mm }{ }^{2}\right)\end{array}$ & $\begin{array}{l}\text { Stress of } \\
\text { Tow } \\
\text { Hook } \\
\left(\mathbf{N} / \mathbf{m m}^{2}\right)\end{array}$ \\
\hline 1 & Pull & 2.7 & 347.1 & 211.7 \\
\hline 2 & Push & 2.7 & 347.1 & 211.7 \\
\hline 3 & $30^{0}$ up & 2.3 & 273.2 & 207.9 \\
\hline 4 & $30^{0}$ down & 5.7 & 479.0 & 253.6 \\
\hline
\end{tabular}

Material wise comparison also done to choose best material and to optimize the design. Following figures shows material wise comparison at various loading conditions.

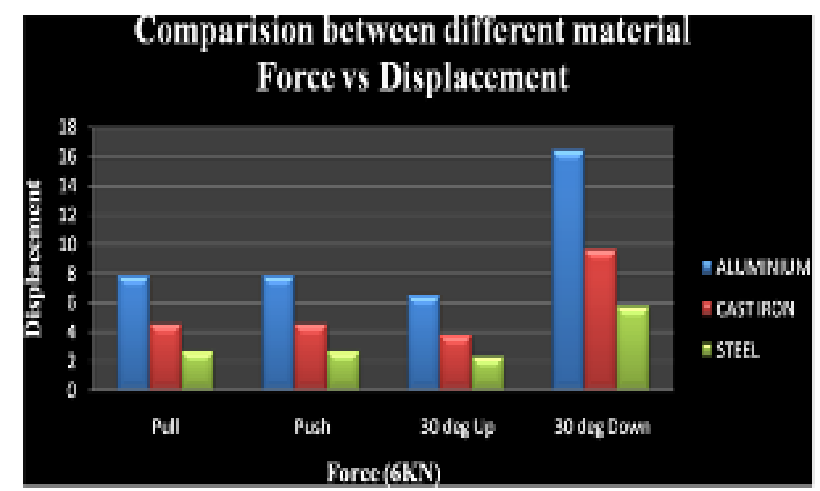

Fig 12: Force v/s displacement for different materials
The above graph shows the material wise comparision for Aluminium, Cast iron and Stainless steel by plotting the graph of Force vs Diasplacement, Where the displacement for aluminium is higher and for stainless steel is very low.

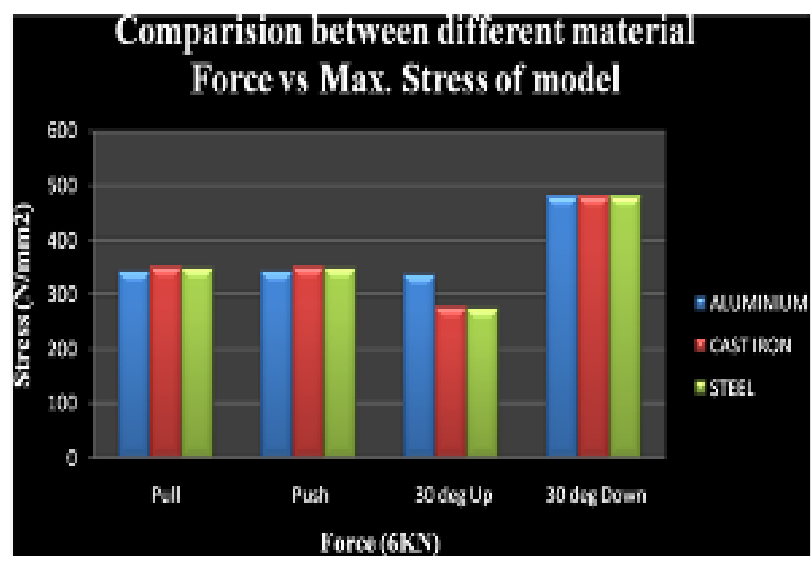

Fig 13: Force v/s Maximum stress graph

The stress values obtained with different loading and material combinations are indicated by graphs lines as shown in the above graph which is a plot of force vs stress of complete model.

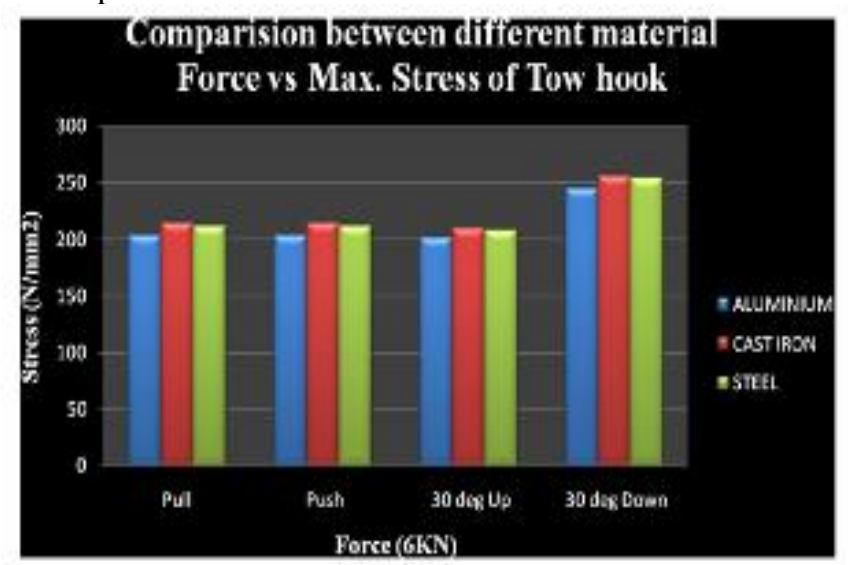

Fig 14: Force v/s Maximum stress of Tow hook Using the values of Maximum Stress obtained from the Tow hook for three different material combinations graph is plotted as indicated in the graph.

\section{RESULTS AND DISCUSSIONS}

The natural frequency obtained for model 1 is $494.7 \mathrm{~Hz}$ (1.151e-03Ton) and for the model 2 is $262.7 \mathrm{~Hz}(4.206 \mathrm{e}-$ 03Ton) of which both the $1^{\text {st }}$ modes are bending modes, hence it can withstand further conditions. The natural frequency with higher values is chosen because it has less mass compared to model 2 .

Further Static analysis was carried out to find stresses and displacements at different loading conditions (push, pull, $30^{\circ}$ up and $30^{\circ}$ down) for the materials Aluminium, Cast iron, Stainless steel. In these obtained values when we refer to graphs or table, we can clearly see that Stainless steel has less stress and displacement values as compared to Cast iron and Aluminum. Stainless steel can withstand maximum loads with less displacement and stress. 


\section{CONCLUSION}

In this study work optimization study of tow hook of commercial vehicle to improve the performance on different loading condition has been done by considering different materials like aluminium, cast iron and stainless steel.

Initially two tow hook designs are selected based on the vehicle requirement and considered the same designs for the optimization process to reduce weight of the models. For meshing of the models HYPERMESH software and for the analysis NASTRAN were used. Analysis of both models was done at different loading conditions for different materials by setting appropriate boundary conditions. From the analysis results it has been concluded that steel is the best material to manufacture the selected tow hook design because it can withstand maximum loads with less displacement and stress.

\section{REFERENCES}

[1]. Abhishek Adnoor, H. L. Guruprasd and B. H. Maurthi, Nonlinear Buckling Analysis of a Tow Bar, indian j.sci.res. 9 (1): 088-095, 2014 issn: 0976-2876, doi: 10.5958/22500138.2014.00015.7.

[2]. Zhiping Wan, Car Front Towing Hook Analysis and Structural Improvements Based on CAE, International Industrial Informatics and Computer Engineering Conference (IIICEC 2015), china.

[3]. Pankaj Khannade, Akash Chitnis, Gangadhar Jagdale, Design and Stress Analysis of Tow Bar for Medium Size Portable Compressor, IJREAT International Journal of Research in Engineering \& Advanced Technology, Volume 2, Issue 3, June-July, 2014, ISSN: 2320 - 8791.

[4]. Santosh Sahu, Ritesh Dewangan, Manas Patnaik, Narendra Yadav, Study of Crane Hook Having Trapezoidal Section by Finite Element Method \& Design of Experiments, International Journal of Modern Engineering Research (IJMER), Vol.2, Issue.4, July -Aug 2012 pp-27792781 ISSN: 2249-6645.

[5]. Ahmad O. Moaaz, Nouby M. Ghazaly, A Review of the Fatigue Analysis of Heavy Duty Truck Frames, American Journal of Engineering Research (AJER), e-ISSN : 23200847 p-ISSN : 2320-0936, Volume-3, Issue-10, pp-01-06. 